\title{
Normal pressure hydrocephalus presenting as Parkinson's syndrome
}

\author{
A. Miodrag, T. K. Das and R. J. Shepherd \\ Department of Geriatric Medicine, Leicester General Hospital, Gwendolen Road, Leicester LE5 4PW, UK.
}

\begin{abstract}
Summary: Although extrapyramidal features in normal pressure hydrocephalus (NPH) are not uncommon, fresentations with Parkinson's syndrome as the predominant feature are rare and may give rise to diagnostic difficulties. Failure of patients with parkinsonism to respond to therapy, should alert one to the possibility of NPH.
\end{abstract}

\section{Introduction}

There is universal acceptance of Hakim \& Adams ${ }^{1}$ original description of the clinical features of normal pressure hydrocephalus (NPH); namely, the triad of gait disturbance, dementia and urinary incontinence. This is associated with dilatation of the ventricular system of the brain without clinical evidence of raised intracranial pressure. There are wide variations in the clinical manifestations of NPH, particularly in regard to the disturbance of gait. This is most often a spastic ataxia, ${ }^{2}$ although less commonly, parkinsonian features can occur. ${ }^{3}$ Rarely patients may present atypically with signs indistinguishable from Parkinson's syndrome., 4

We report a case of normal pressure hydrocephalus in whom the initial manifestation was that of Parkinson's syndrome, which resolved completely following the insertion of a ventriculo-peritoneal shunt.

\section{Case report}

A previously fit and active 71 year old woman was admitted with an 18 month history of tremor of the hands and progressive difficulty in walking. Parkinson's syndrome had been diagnosed by a neurologist who commenced treatment with amantadine, but despite this her walking continued to deteriorate with numerous backward falls. She was virtually bed bound for 2 weeks before admission and was incontinent of urine for 6 months.

On examination she looked healthy, was a little forgetful but well orientated. Tendon reflexes were generally brisk, particularly in the legs, with bilateral extensor plantar responses. Tone was increased in all limbs with cogwheeling rigidity of both wrists. There

Correspondence: A. Miodrag B.Sc., M.R.C.P.

Accepted: 18 August 1986 was slight weakness of the legs but sensation was normal. She was bradykinetic and could take only a few retropulsive, wide based shuffling steps between two nurses. The rest of the examination, including fundoscopy, was normal.

Haematological and biochemical screen and chest $\mathrm{X}$-ray were normal. X-ray of spine revealed spondylitic changes in the cervical and dorso-lumbar spine. In view of her paraparesis a myelogram was done, which showed no evidence of cord compression. Cerebrospinal fluid (CSF) pressure and protein content were normal.

There was little improvement in her walking despite intensive physiotherapy and the addition of levodopa/ carbidopa (Sinemet) and selegiline (Eldepryl) to her medication. Over the next 2 months she was intermittently confused, forgetful, aggressive and abusive. She remained parkinsonian, ataxic and incontinent of urine. A computed tomographic (CT) head scan (Figure 1) showed enlargement of the ventricles with normal cerebral sulcii, consistent with normal pressure hydrocephalus. She was referred to a neurosurgical unit where a ventriculo-peritoneal shunt was inserted. CSF pressure at operation was normal. Four weeks post-operatively her urinary incontinence resolved and by 6 weeks her plantar responses were flexor. There were no signs of parkinsonism and her confusion cleared, with no recurrence of symptoms on stopping all her medication. By 8 weeks she was independent, walking well with a Zimmer frame and could climb stairs. She was discharged home.

\section{Discussion}

The clinical features of NPH are due to the selective involvement of periventricular regions of the brain ${ }^{6}$ consequent upon progressive ventricular enlargement. 


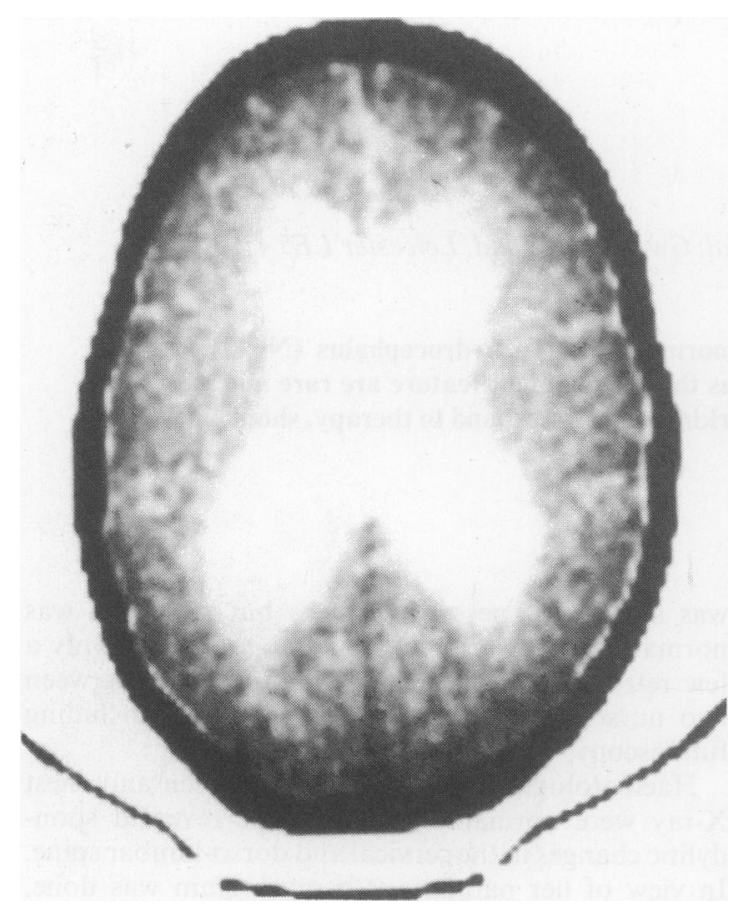

Figure 1 CT head scan showing ventricular enlargement with normal cerebral sulcii.

Pathological findings include ventricular ependymal disruption, subependymal gliosis, periventricular white matter oedema and loss of myelin staining and destruction of nerve fibres in the periventricular areas. ${ }^{7}$ Involvement of leg and bladder efferent fibres as they sweep past the dilated frontal horns of the

\section{References}

1. Hakim, S. \& Adams, R.D. The special clinical problem of symptomatic hydrocephalus with normal cerebrospinal fluid pressure - observations on cerebrospinal fluid hydrodynamics. J Neurosurg Sci 1965, 2: 307-327.

2. Ojemann, R.G., Fisher, C.M., Adams, R.D., Sweet, W.H. \& New, P.J.F. Further experience with the syndrome of 'normal' pressure hydrocephalus. J Neurosurg 1969, 31: 279-294.

3. Messert, B. \& Baker, N.H. Syndrome of progressive spastic ataxia and apraxia associated with occult hydrocephalus. Neurology 1966, 16: 440-451.

4. Sypert, G.W., Leffman, H. \& Ojemann, G.A. Occult normal pressure hydrocephalus manifested by Parkinsonism-dementia complex. Neurology 1973, 23: $234-$ 235. lateral ventricles; accounts for paraparesis and incon- $\frac{3}{2}$ tinence. ${ }^{8}$ Involvement of the terminal dopaminergic $\bigcirc$

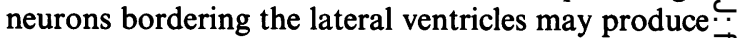
extrapyramidal symptoms. ${ }^{9}$ Edvinsson et al. ${ }^{9}$ demon- $\overrightarrow{\overrightarrow{\vec{s}}}$ strated a significant progressive decline in fore and -5 mid brain dopamine and homovanillic acid content in $\frac{\bar{\sigma}}{\sigma}$ rabbits one month after producing experimental nor $-\overline{\bar{c}}$. mal pressure hydrocephalus. Sypert et al. ${ }^{4}$ reported $\widehat{\nabla}$

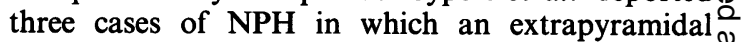
syndrome was the predominant manifestation, with ${ }^{\infty}$ resolution following shunt insertion. Mazza et al..$^{5} \vec{\circ}$ reported a similar case, with mild improvement post shunt. Sypert et al. $^{4}$ suggested that parkinsonian $\omega_{\sigma}$ symptoms in NPH are the result of mechanicalo distortion of the basal ganglia and consequent vas- $\frac{0}{3}$ cular insufficiency in the nigrostriatal system. In the same way, local distortion of the basal ganglia and mid $\omega$ brain by tumour can produce parkinsonian symptoms $\omega े$ that disappear after successful decompression. ${ }^{10}$

The original report ${ }^{1}$ of NPH being an eminently $\overrightarrow{\vec{\omega}}$ treatable cause of dementia led to an explosion of 을 shunt insertions in demented patients. This was often inappropriate due to the inclusion of patients with $\vec{T}$ cerebral atrophy (hydrocephalus ex vacuo) who do not $\frac{\mathbb{D}}{\mathrm{O}}$ respond to shunting. ${ }^{2}$ Clinical features alone are insufficient to make a diagnosis of NPH, but can raise the possibility. Other causes of dementia, such $\underset{\alpha}{\Omega} \overrightarrow{0}$ Alzheimer's disease, can be associated with gait distuk bance and incontinence, ${ }^{2}$ but in NPH gait is usuales. severely impaired before significant mental changess are apparent. ${ }^{11}$ Diagnostic tests include; CT scanning, ${ }^{12}$ isotopic cysternography, ${ }^{13}$ clinical response to test removal of $\mathrm{CSF}^{14}$ and intracranial pressure monitoring. ${ }^{15}$

Overall, about $50 \%$ of patients improve after a shunt procedure ${ }^{16}$ with best results in subjects in whom gait disturbance is the predominant feature and vice versa where dementia is predominant. ${ }^{17}$

5. Mazza, S., Laudisio, A. \& Bergonzi, P. Occult normal pressure hydrocephalus with parkinsonian symptomatology. Eur Neurol 1976, 14: 39-42.

6. Weller, R.O., Wisniewski, H., Ishii, N., Shulman, K. \& Terry, R.O. Brain tissue damage in hydrocephalus. Dev N Med Child Neurol (Suppl) 1969, 20: 1-7.

7. DiRocco, C., DiTrapani, G. \& Maira, G. Anatomo- N clinical correlations in normotensive hydrocephalus. N

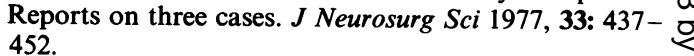

8. Yakolev, P.I. Paraplegias of hydrocephalus: Clinical note and interpretation. Am J Ment Defic 1947, 51: 561 576.

9. Edvinsson, L., Nielsen, K.C., Owman, Ch., Rosengren, E. \& West, K.A. Concomitant fall in brain dopamine and 
homovanillic acid in hydrocephalic rabbits. Exp Neurol 1972, 37: 647-649.

10. Oliver, L. Parkinsonism due to mid brain compression. Lancet 1959, ii: 817-819.

11. Pickard, J.D. Adult communicating hydrocephalus. $\mathrm{Br} J$ Hosp Med 1982, 27: 35-44.

12. Moseley, I.F. \& Radii, E.W. Factors influencing the development of periventricular lucencies in patients with raised intracranial pressure. Neuroradiology 1979, 17: 65-69.

13. Katzman, R. Normal pressure hydrocephalus. Contemporary Neurology Series 1977, 15: 69-92.
14. Fisher, C.M. Communicating hydrocephalus. Lancet 1978, i: 37 (letter).

15. Chawla, J.C., Hulme, A. \& Cooper, R. Intracranial pressure in patients with dementia and communicating hydrocephalus. J Neurosurg 1974, 40: 376-380.

16. Black, P.McL. Idiopathic normal pressure hydrocephalus. Results of shunting in 62 patients. $J$ Neurosurg 1980, 52: $371-377$.

17. Jacobs, L., Conti, D., Kinkel, W.R. \& Manning, E.J. "Normal pressure" hydrocephalus. Relationship of clinical and radiographic findings to improvement following shunt surgery. J Am Med Assoc 1976, 235: 510-512. 